\title{
Low dose radiation and childhood cancer
}

\author{
J A Morris
}

There is evidence of an increased risk of childhood acute leukaemia in the vicinity of nuclear installations. ${ }^{1}$ This applies in particular to the village of Seascale, West Cumbria, which is close to the Sellafield nuclear plant. ${ }^{23}$ There is an increased incidence of childhood leukaemia in children who are born there, but this is not found in children who move to the village later and attend the local school. More recently it has been shown that men who work at Sellafield are at increased risk of fathering a child with leukaemia, and this is related to the level of preconceptual radiation exposure.

Radiation is a known mutagen but the calculated doses to men in the plant and children in the nearby village appear to be far less than required to explain the observed excess of leukaemia. ${ }^{5}$ In view of this other explanations have been sought. The population of Seascale is unusual in that it consists predominantly of higher socioeconomic groups, mobility is high, and the area is isolated. All these factors have been shown to increase the incidence of childhood leukaemia, ${ }^{6-8}$ and it is suggested that this might be related in some way to an altered response to infection..$^{6-9}$

More recently it has been shown that there is an extraordinary cluster of cases of retinoblastoma linked to residence in Seascale. ${ }^{1011}$ This raises once again the possibility of a link with radiation but the same arguments can be used; conventional dose estimates and risk estimates indicate that the level of exposure is insufficient to account for the observed excess.

In this paper a recently published model of leukaemogenesis ${ }^{12}$ is used to reassess the evidence linking radiation dose to leukaemia incidence in this area. It is shown that the gap between observed excess and expected increase is not as wide as has been previously claimed. ${ }^{5}$

\section{A model of leukaemogenesis}

Recent advances in molecular biology have indicated that a malignant clone of cells will arise when a single cell has accumulated a number of rare mutations influencing the activity of growth control genes. If the mutation rate per gene per cell generation is $m$, and $n$ specific independent mutations are required for leukaemogenesis it can be shown that ${ }^{12}$

$$
N=\sum_{x=1}^{x}\left[(m x)^{n}-[m(x-1)]^{n}\right] 2^{x}
$$

where $N=$ expected number of neoplasms $x=$ number of cell generations
This equation has been applied to kinetic and epidemiological data on acute lymphoblastic leukaemia (ALL). ${ }^{12}$ The best fit is obtained if $m$ is approximately $1 \times 10^{-6}$ and $n=4$. The chance of a child developing ALL by age 15 years is of the order of $4 \times 10^{-4}$. The equation has also been applied to retinoblastoma, ${ }^{13}$ in which case $n=2$ and the best estimate of $m$ is $8 \times 10^{-8}$. There are theoretical reasons for believing that the mutation rate in developing lymphocytes might be higher than in other cells. ${ }^{14}$

An interesting prediction of the model is that if the mutation rate is increased for all cell divisions throughout all cell generations then the increased incidence of ALL will be proportional to the mutation rate raised to the power $n$. Thus a doubling of the mutation rate will lead to a 16-fold increase in the incidence of ALL. If the mutation rate is doubled for the last two or three cell generations this will only double the incidence even though $75 \%$ of all cell divisions occur in the last two generations. ${ }^{12}$

Environmental radiation and leukaemia Gardner $e t ~ a l^{3}$ noted that in children born in Seascale the ratio between observed and expected cases of childhood leukaemia was 9.36 (95\% CI 3.04 to $21 \cdot 84)$. There are, however, two main reasons why the ratio of 9 might be an overestimate. The first is that clusters of rare childhood cancers are only noted and published when there is a gross excess overexpectation. This process of selection means that published risk ratios will tend to overestimate the true ratio. Secondly, there is good evidence that the characteristics of the Seascale population, such as high socioeconomic class, mobility, and relative isolation will lead to an increased expectation of leukaemia over national rates. ${ }^{6-8}$

Previous attempts to investigate the relationship between contamination of the environment by radionuclides and the risk of leukaemia have been based on: ${ }^{5}(1)$ estimating the cumulative radiation dose to age 20 years for children born and reared in Seascale, and (2) calculating the number of additional cases of leukaemia induced using risk factors based on the effects of acute radiation exposure at Hiroshima, in patients treated for ankylosing spondylitis and in children irradiated in utero. There are two major problems with this approach. Firstly, the incidence of ALL rises rapidly to a peak at about 3-4 years of age and then falls rapidly ${ }^{15}$ so that the cumulative 
Table 1 Predicted mutant frequency and tumour incidence in a conceptual experiment in which one cell undergoes 53 successive doublings to produce $9 \times 10^{15}$ cells $\star$

\begin{tabular}{lrl}
\hline Condition & Mutant frequency & Tumour incidence $(n=4)$ \\
\hline A & $53 \times 10^{-7}$ & $1 \times 10^{-6}$ \\
B & $2 \times 10^{-7}$ & $1.44 \times 10^{-11}$ \\
C & $104 \times 10^{-7}$ & $7.8 \times 10^{-6}$ \\
\hline
\end{tabular}

$A=$ unit of radiation over 12 months.

$B=$ unit of radiation in second 6 months.

$C=$ unit of radiation in first 6 months.

*It is assumed that the number of cell divisions per unit time is C It is assumed that the number of cell divisions per unit time is months.

radiation exposure to 20 years is not relevant. Secondly, the effect of an acute dose of radiation can be quite different from that of continuous low dose radiation.

The latter point can be illustrated by the following conceptual experiment based on the above model. A single cell is placed in a large fluid medium and allowed to divide through 53 generations to produce $9 \times 10^{15}$ cells (this is approximately the number of cells produced in a human lifetime). Conditions are arranged so that the entire process takes 12 months and the number of divisions per unit time after the first month is constant. In this hypothetical model mutation only occurs in the presence of radiation and the mutation rate is proportional to the dose. If the medium has a constant low level of radiation sufficient to produce a mutation rate of $1 \times 10^{-7}$ per gene per cell division then the mutant frequency of any single allele in the final cells will be $53 \times 10^{-7}$ (table 1). If, however, the same total dose of radiation is given in the second 6 months the mutation rate will be $2 \times 10^{-7}$ but only the last generation will be affected. Thus the final mutant frequency will be $2 \times 10^{-7}$. If the radiation is given in the first 6 months the mutation rate will be $2 \times 10^{-7}$ for the first 52 generations and the final mutant frequency will be $104 \times 10^{-7}$. The expected number of tumours produced under these three different conditions, for $n=4$, is shown in table 1 . The same dose of radiation could have a neoplastic potential varying 100000 fold. It is clearly not safe to extrapolate from acute exposure to low dose chronic exposure.

Another problem is that of critical groups who might be exposed to an unusually high level of radiation. If there is a linear relationship between radiation dose and the risk of leukaemia then the fact that the total dose of

Table 2 Annual absorbed dose of radiation to the lower large intestine from all sources for individuals living in Seascales

\begin{tabular}{lll}
\hline & \multicolumn{2}{l}{ Annual dose $(m G y)$} \\
\cline { 2 - 3 } Year & Low LET & High LET \\
\hline 1955 & 2.0 & 0.004 \\
1960 & 2.1 & 0.002 \\
1965 & 1.7 & 0.002 \\
1970 & 1.8 & 0.002 \\
1975 & 1.9 & 0.003 \\
\hline
\end{tabular}

LET $=$ linear energy transfer. radiation might be spread unevenly through the population will not affect the expected number of cases. This is the assumption that has been made previously. ${ }^{5}$ In the case of low dose continuous exposure during fetal development, however, the model indicates a quartic relation between dose and incidence. This has a quite different effect. For instance if a dose of radiation sufficient to double the mutation rate is given to the entire population the incidence of ALL would rise 16 fold. If the same total dose was concentrated on half the population then the mutation rate would be tripled in this group and the incidence of ALL in the entire population would rise 41 times $\left[3^{4} / 2+1 / 2\right]$.

In order to determine the effects of environmental radiation it is necessary to know the level of natural background radiation, the average annual dose to the fetus and infant from Sellafield discharges, as well as other artificial sources of radiation, the extent to which the distribution of the dose is uneven, and what fraction of the spontaneous mutation rate of cells is due to background radiation.

The level of background radiation to human tissues is approximately $1 \mathrm{mGy}$ per annum. The dose to the fetus and infant from other sources is rather more difficult to determine. Table 2 shows the annual dose to the lower large intestine for an individual living in Seascale (strictly it is for an individual born in 1950 in Seascale). ${ }^{5}$ The dose is mainly from low linear energy transfer radiation (low LET) which is the most penetrating. The fetus develops in utero surrounded by loops of small intestine and encircled by the large intestine. Thus the dose to the intestine is the best proxy for the fetal dose which is available from NRPB data. ${ }^{5}$ In many years the total dose was double natural background and in 1 year, 1954, the annual low LET dose to the large intestine was $3.6 \mathrm{mGy} .^{5}$ Over the period of operation of the Sellafield plant it has been estimated that $53.4 \%$ of the dose in table 2 was due to natural background radiation, $24.3 \%$ due to Sellafield discharges, $12.5 \%$ due to nuclear fallout, $2 \cdot 2 \%$ due to the Windscale fire, and $7.6 \%$ due to medical radiation. Thus if human tissues receive approximately $1 \mathrm{mGy}$ per annum due to natural background radiation, Sellafield discharges have irradiated fetuses at a rate equivalent to $0.45 \mathrm{mGy}$ per annum. This represents a one third increase over other sources.

The extent to which the spontaneous mutation rate in cells is due to background radiation is not known. Thus in table 3 the effect on the expectation of childhood leukaemia is calculated for the varying value of this relationship. The assumption that the dose is evenly distributed (column 2) will underestimate the increased risk. The degree of heterogeneity of dose is, however, not known and therefore the figures in column 3 are purely to illustrate the potential effect of an uneven dose distribution. The worst case assumption is that the spontaneous mutation rate is entirely due to background radiation, in 
Table 3 Theoretical risk ratio of ALL in children born in Seascale as predicted by the model using varying values of the relation between background radiation and spontaneous mutation rate ${ }^{\star}$

\begin{tabular}{|c|c|c|}
\hline $\begin{array}{l}\text { \% of spontaneous mutation } \\
\text { rate due to background } \\
\text { radiation (natural and } \\
\text { artificial but excluding } \\
\text { Sellafield discharges) }\end{array}$ & $\begin{array}{l}\text { Increase in } A L L \text { if } \\
\text { the additional dose } \\
\text { due to Sellafield } \\
\text { discharges is } 1 / 3 \text { of } \\
\text { other sources }\end{array}$ & $\begin{array}{l}\text { Increase in } A L L \text { if additional dose } \\
\text { due to Sellafield discharges is } 1 / 3 \text { for } \\
90 \% \text { of the population but ten times } \\
\text { as high as this for } 10 \% \text { of the } \\
\text { population }\end{array}$ \\
\hline $\begin{array}{r}10 \\
20 \\
30 \\
40 \\
50 \\
60 \\
70 \\
80 \\
90 \\
100\end{array}$ & $\begin{array}{l}1.14 \\
1.29 \\
1.46 \\
1.64 \\
1.84 \\
2.06 \\
2.29 \\
2.55 \\
2.83 \\
3.13\end{array}$ & $\begin{array}{r}1.34 \\
1.92 \\
2.88 \\
4.37 \\
6.59 \\
9.74 \\
14.06 \\
19.85 \\
27.39 \\
36.99\end{array}$ \\
\hline
\end{tabular}

*The second column assumes an even distribution of radiation in the community while the third column assumes an uneven distribution. which case Sellafield discharges will increase the risk of ALL to children born in Seascale by between 3 and 37 times. This analysis should be compared with that in the Black report ${ }^{16}$ in which the worst case assumption caused only a small increase in the expectation of leukaemia. It can be seen from table 3 that even if background radiation is only responsible for a part of the spontaneous mutation rate then the gap between the observed increase in leukaemia and that expected is less than previously claimed.

\section{Discussion}

It is usually assumed that risk estimates of cancer based on acute doses of radiation will overestimate the number of cancers produced by low dose radiation. ${ }^{16}$ This is because if a dose of radiation is given in several small fractions the mutagenic effect is less than that of a single dose. The usual explanation for this is that DNA repair mechanisms will correct the effects of a small dose but are more likely to be overwhelmed by a large dose. The analysis in this paper, however, shows that there is another mechanism which can lead to a gross underestimate of the oncogenic potential of low dose continuous radiation. If the radiation acts on all cell generations from the single cell stage then the mutagenic effect accumulates and in the case of leukaemia this model predicts a quartic relationship between radiation dose and cancer incidence.

The human tissue which receives the largest percentage increase in radiation dose due to Sellafield discharges to the environment is the intestine. $^{5}$ This is because the route of exposure is mainly by ingestion and many of the radionuclides are not absorbed. Most of the increase is due to low LET radiation which is the most penetrating (table 2). This means that the position of the fetus in utero, surrounded by small and large intestine, is the worst possible as far as the mutagenic effects of Sellafield discharges are concerned.

An important difference between this analysis and previous analyses relates to the consequence of an uneven distribution of environmental radiation over time and between individuals. This has no effect on the expected increase in leukaemia if there is a linear relationship between dose and incidence, but it will have a marked effect if the incidence is proportional to the dose raised to the power four, as suggested by this model of leukaemogenesis. ${ }^{12}$ In this context it is important to note that of the 53 to 60 cell generations required to produce the cells of the body, ${ }^{12}$ the first 30 occur in the first month of intrauterine life. If only a small fraction of pregnant women are exposed to an increased dose of radiation at this time it could have a marked effect on the overall incidence.

The model can also be used to address the possibility that radiation to Sellafield workers induces a germinal mutation which leads to the observed increase in leukaemia. ${ }^{4}$ In fact this analysis has been presented elsewhere. ${ }^{17}$ To get a threefold increase in the incidence of leukaemia requires a 30-300 fold increase in the sperm mutation rate. This is far less plausible than an increase in somatic mutation rate of one third.

The model demonstrates that on the worst case assumption, which is that the spontaneous mutation rate is entirely due to background radiation, the calculated dose to the population is enough to explain the observed increase in leukaemia incidence. It is only if natural background radiation contributes less than $20 \%$ to the spontaneous mutation rate that the gap between that observed and that expected starts to widen considerably. Even then the gap is less than in previous analyses.

\section{Conclusion}

The model of leukaemogenesis used in this paper shows that if radiation acts on all cell generations throughout fetal development then there is a quartic relationship between radiation dose and leukaemia incidence. A consequence of this is that critical groups with a high radiation dose will have a disproportionate increase in their rate of leukaemia. The precise risk in a population, however, will depend on the fraction of the spontaneous mutation rate which is caused by natural background radiation and the heterogeneity of radiation dose within the population. Neither of these is known with certainty but the model shows that reasonable assumptions result in a range of predicted risk ratios which are much higher than in previous analyses of this problem. Thus although the observed increase of ALL in Seascale could be in part due to chance and in part due to other factors, such as infection, the contribution from Sellafield discharges seems greater than previously suggested.

1 Forman D, Cook-Mozaffari P, Darby S, Davey G, Stratton I Doll R, et al. Cancer near nuclear installations. Nature 1987;329:499-505.

2 Gardner MJ, Hall AJ, Downes S, Terrell JD. Follow up study of children born elsewhere but attending schools in Seascale, West Cumbria (schools cohort). Br Med 1987;295:819-22.

3 Gardner MJ, Hall AJ, Downes S, Terrell JD. Follow up study of children born to mothers resident in Seascale West Cumbria (birth cohort). Br Med J 1987;295:822-7. 4 Gardner MJ, Snee MP, Hall AJ, Powell CA, Downes S, 
Terrell JD. Results of case control study of leukaemia and lymphoma among young people near Sellafield nuclear plant in Cumbria. Br Med J 1990;300:423-9.

5 Stather JW, Dionian J, Brown J, Fell TP, Muirhead CR The risk of leukaemia and other cancers in Seascale from radiation exposure-Addendum to report R171. NRPBR171. Oxford: National Radiological Protection Board, 1986.

6 Kinlen L. Evidence for an infective cause of childhood leukaemia: comparison of a Scottish new town with nuclear reprocessing sites in Britain. Lancet 1988;ii 1323-7.

7 Kinlen L, Clark K, Hudson C. Evidence from population mixing in British New Towns 1946-1985 of an infective basis for childhood leukaemia Lancet 1990;336:577-82.

8 Alexander FE, Ricketts TJ, McKinney PA, Cartwright RA. Community lifestyle characteristics and risk of acute lymphoblastic leukaemia in children. Lancet 1990; 336:1461-5.

9 Greaves MF. Speculations on the cause of childhood acute lymphoblastic leukaemia. Leukaemia 1988;2:120-5.
10 Morris JA, Edwards JM, Buckler J. Retinoblastoma in grandchildren of workers at Sellafield nuclear plant. $B r$ Med J 1990;302:112-30.

11 Morris JA, Buckler J. Retinoblastoma linked to Seascale, West Cumbria. Br Med J 1991;302:112-3.

12 Morris JA. A mutational theory of leukaemogenesis. J Clin Pathol 1989;42:337-40.

13 Morris JA. Spontaneous mutation rate in retinoblastoma. $J$ Clin Pathol 1990;43:496-8.

14 Greaves MF. Is spontaneous mutation the major cause of childhood acute lymphoblastic leukaemia? $\mathrm{Br} J$ Haematol 1986;64:1-13.

15 Greaves MF, Pegram SM, Chan LC. Collaborative group study of the epidemiology of acute lymphoblastic leukaemia subtypes: background and first report. Leuk Res 1985;9:715-33.

16 Black D. Investigation of the possible increased incidence of cancer in West Cumbria. Report of the independent advisory group. London: HMSO, 1984.

17 Morris JA. Leukaemia and lymphoma among young people near Sellafield. Br Med J 1990;300:676. 